\title{
Relações entre pesquisa em ensino de Ciências e formação de professores: algumas representações
}

Maria José P. M. de Almeidal

Roberto Nardi"

\section{Resumo}

Este estudo foi realizado com o objetivo de investigar representações de pesquisadores da área de ensino de Física sobre a possível interferência da pesquisa da área de ensino de Ciências na maneira como se formam professores no Brasil. Para tal, foram analisadas as respostas a uma questão formulada em entrevistas a treze pesquisadores do ensino da Física, indicados por seus pares por meio de correio eletrônico encaminhado a pesquisadores do ensino de Ciências, incluindo as subáreas de Biologia, Física, Geociências e Química. A análise de discurso desenvolvida na França por Michel Pêcheux, a partir de subsídios obtidos principalmente em publicações de Eni Orlandi no Brasil, foi o apoio teórico que sustentou o estudo. As representações que os discursos selecionados permitem inferir evidenciam pequena influência. Entretanto, foram enunciados fatores de grande abrangência, incluindo desde aqueles internos à própria área, quanto fatores associados a políticas públicas. Também se observou uma diversidade de posições entre os pesquisadores entrevistados. No conjunto, os fatores abordados pelos entrevistados constituem um amplo quadro configurativo de representações que pode ser elemento de reflexão para outros pesquisadores. Acreditamos que essas representações têm potencial de contribuição para efetivas interferências na forma de realização de políticas públicas, sem a necessidade do uso de prescrições e cada vez menos com recomendações vazias.

\section{Palavras-chave}

Ensino de Ciências - Formação de professores - Análise de discurso - Representações.

I-Apoio do CNPq. Universidade Estadual de Campinas, Campinas, SP, Brasil.

Contato: mjpma@unicamp.br

II- Apoio da FAPESP e da Fundação para o Desenvolvimento da UNESP. Universidade Estadual Paulista "Júlio de Mesquita Filho", Bauru, SP, Brasil.

Contato: nardi@fc.unesp.br 


\section{The relations between research in Science teaching and teacher education: representations}

Maria José P. M. de Almeida'

Roberto Nardill

I- The author acknowledges the support

of CNPq. Universidade Estadual de Campinas, SP, Brazil.

Contact:mjpma@unicamp.br

II- The author acknowledges the support of FAPESP and of the UNESP Development Foundation. Universidade Estadual Paulista "Júlio de Mesquita Filho", Bauru, SP, Brazil.

Contact: nardi@fc.unesp.br

\begin{abstract}
This study was conducted with the objective of investigating representations of researchers from the area of the teaching of Physics about the possible influence of the research in the area of Science teaching upon the way in which teachers are educated in Brazil. For that, an analysis was made of the answers to a question formulated in interviews made with 13 researchers from the field of the teaching of Physics, which were indicated by their peers through an electronic mail sent to researchers in Science teaching, including the subareas of Biology, Physics, Geosciences and Chemistry. The discourse analysis developed in France by Michel Pêcheux, based on elements obtained mainly from publications by Eni Orlandi in Brazil, gave the theoretical support to the study. The representations that the selected discourses allowed to infer suggest that the abovementioned influence is small. However, factors of great import were mentioned, including factors internal to the area, as well as factors associated to public policies. A wide diversity of positions among the researchers interviewed could also be observed. On the whole, the factors mentioned by the interviewees constitute a wide configuration scenario of representations that can be an element for reflection to other researchers. We believe that these representations have the potential to contribute to the appearance of effective influences in the form of the development of public policies, without the need for prescriptions and with fewer and fewer empty recommendations.
\end{abstract}

\section{Keywords}

Science teaching - Teacher education - Discourse analysis - Representations. 
No Brasil, assim como em outros países, é evidente a ampla focalização de estudos da área educacional sobre o professor, os papéis sociais por ele exercidos, o que ele deve ou não fazer profissionalmente e como deve ser sua formação, tanto a inicial quanto a continuada. Essa focalização se manifesta na grande e diversificada quantidade de publicações - em anais de congressos, periódicos e livros - que incluem o professor como figura central. Apenas para ilustrar esse fato, citamos aqui os autores de alguns dos livros a esse respeito editados nas três últimas décadas no país: Martins (1984); Catani et al. (1986); Ribeiro (1987); Feracine (1990); Becker (1995); Menezes (1996b); Rangel (1996); Brzezinski (1997); Pimenta (1997); Gatti (1997); Giroux (1997); Kincheloe (1997); Geraldi et al. (1998); Goergen e Saviani (1998); Contreras (2002); Perrenoud (2002); Pereira (2003); Alves (2004); Facci (2004), Tardif e Lessard (2008). Dossiês em periódicos também são registro do grande interesse que a pesquisa em educação vem tendo pelo professor já há bastante tempo. Entre eles estão: $O$ professor e o ensino: novos olhares, publicado em um dos números do Caderno Cedes de 1998; Formação de profissionais da educação: politicas e tendências, de 1999, e Os saberes dos docentes e sua formação, de 2001, ambos editados pela revista Educação e Sociedade.

Trata-se de um interesse voltado a problemas comumente associados à escola e ao ensino que ali se pratica. Tais problemas geram questões de estudo que, por sua vez, possibilitam análises realizadas com o apoio de diferentes tendências teóricas, as quais não se limitam à geração de metodologias de análise, pois contêm concepções sobre o professor que interferem no próprio estabelecimento do problema a ser analisado.

Essa ampla focalização evidencia, sobretudo, a relevância do professor em nossa sociedade, independentemente de se tratar de um estudo de caso sobre a maneira como determinado professor ensina certo conteúdo, ou de uma reflexão sobre políticas públicas relativas à formação ou à atuação profissional. As concepções explicitadas ou subentendidas nos estudos são de natureza bastante variada. Apenas para ilustrar a ampla gama dessas concepções, constatamos que não é difícil encontrar estudos recentes nos quais o professor é o indivíduo detentor de conhecimentos que devem ser passados aos alunos, ou estudos cujo foco está na maneira como ele atua enquanto mediador de atividades realizadas pelos estudantes.

A relevância do professor também pode ser notada quando se olha para uma das subáreas da educação: no caso, o ensino de Ciências. Nela se observa o mesmo interesse acadêmico pela figura do professor, interesse este que se traduz num grande número de publicações nas últimas três décadas. São exemplos disso os livros dos seguintes autores: Krasilchik (1987); Carvalho e Gil-Pérez (1993); Menezes (1996a); Gioppo (1999); Ostermann e Moreira (1999); Mion e Saito (2001); Selles e Ferreira (2003); Nardi, Bastos e Diniz (2004); Rosa (2004, 2005); Bastos e Nardi (2008). Também na leitura desses textos podemos ver explicitadas ou subentendidas diferentes concepções teóricas e, consequentemente, diferentes concepções sobre o professor, mas em todas elas é possível notar o reconhecimento de sua relevância social.

0 interesse na área de ensino de Ciências por pesquisas que envolvem a formação do professor pode ser avaliado se considerarmos que, no último Encontro Nacional de Pesquisa em Educação em Ciências, realizado no final de 2011 na cidade de Campinas, dos 1.235 trabalhos distribuídos em 14 linhas temáticas do evento e aprovados para apresentação, 385 (31\%) eram relativos à linha formação de professores.

Entretanto, é fato que os consideráveis avanços obtidos em pesquisas estão longe de resolver a maioria das dificuldades encontradas nas ações do professor nos diferentes níveis de ensino. Isso não é de se estranhar, se considerarmos a complexidade do trabalho docente e, principalmente, se admitirmos que as ações desse profissional dependem de múltiplos fatores, não se restringindo à possível influência que o desenvolvimento de pesquisas pode exercer sobre elas. 
Por outro lado, com o aumento das pesquisas na área, alguns avanços podem ser notados. Num estudo em que analisa recomendações direcionadas ao professor de Física, Almeida (2006) classifica como prescrição o ato de dizer ao professor o quê, quando e como ele deve trabalhar com seus alunos. Já as recomendações vazias dirigidas ao profissional são consideradas aquelas sugestões calcadas em resultados satisfatórios para determinados procedimentos de ensino, sem que sejam apresentados os fundamentos e as condições em que foram gerados os procedimentos sugeridos. Em outro estudo, Almeida (2012) localizou inúmeras prescrições em textos de décadas passadas, mas também notou que ainda é possível encontrar prescrições em alguns documentos voltados para a ação docente, sem que, entretanto, elas estejam presentes em trabalhos resultantes de pesquisas. Já quanto às recomendações vazias, o mesmo não ocorre. 0 texto ainda aponta serem atualmente bem mais comuns as parcerias, uma prática que a autora afirma estar bem disseminada na área de ensino de Ciências e que ela julga ter grande potencial para provocar deslocamentos no imaginário de professores do ensino básico e de pesquisadores da universidade. No entanto, é fato que a possibilidade de parceria aplica-se à formação continuada e não esgota as questões relativas ao trabalho do professor e à sua formação, inicial ou continuada.

Por outro lado, dada a amplitude de propostas educacionais e mais especificamente de concepções sobre conteúdos e formas da formação docente que podem ser identificadas na literatura sobre o ensino de Ciências, justifica-se a relevância de se buscar compreender representações de pesquisadores da área, as quais provavelmente têm interferido nas próprias opções de pesquisa desses pesquisadores. Nesse sentido, sendo a formação docente um foco importante entre as questões tratadas na área, julgamos que uma síntese das posições de pesquisadores experientes sobre a influência das pesquisas nessa formação poderia contribuir significativamente para o avanço no direcionamento de futuras investigações.
0 presente estudo insere-se nessa problemática que gera algumas questões, aqui resumidas da seguinte maneira: como os pesquisadores da área entendem a relação entre o desenvolvimento de pesquisas - não apenas aquelas sobre a formação docente, mas as pesquisas da área de uma maneira geral - e a formação docente? Em outros termos: segundo as representações de pesquisadores sobre o ensino de Ciências no Brasil, qual é a relação entre o desenvolvimento de pesquisas na área e a formação docente?

Quanto ao universo do estudo, dadas algumas especificidades relacionadas a cada campo, julgamos conveniente que a análise focalizasse pesquisadores atuantes em uma mesma disciplina. Como instrumento de pesquisa utilizou-se a entrevista, dado que essa é a técnica por excelência para se chegar às representações dos sujeitos.

Desse modo, foram analisados discursos obtidos em entrevistas a pesquisadores da área de ensino de Física, com o objetivo de compreender suas representações acerca da interferência ou não da pesquisa realizada na área de ensino de Ciências sobre a maneira como se formam professores no Brasil. A questão básica foi assim enunciada: como pesquisadores da área de ensino de Física entendem a relação entre o desenvolvimento de pesquisas na educação em Ciências e a formação docente?

\section{Apoio teórico-metodológico}

0 estudo sustenta-se teoricamente em noções da análise do discurso (AD) com base na perspectiva iniciada na França por Michel Pêcheux, utilizando a entrevista como técnica de coleta de informações.

Tal como outras técnicas utilizadas com o intuito de coletar informações, a entrevista pode ser pensada a partir de diferentes referenciais teóricos. Estes são determinantes de possibilidades e limites do que se pode concluir a partir da análise das informações obtidas com a técnica utilizada. Ao nos apoiarmos 
na perspectiva da $\mathrm{AD}$, utilizamos, principalmente, as noções desenvolvidas no Brasil por Eni Orlandi.

Nessa perspectiva, pressupõem-se a não transparência da linguagem e o papel das condições de produção na formulação dos discursos, com destaque para as representações sociais. Em decorrência, as considerações sintetizadas a partir das entrevistas subentendem a relevância das representações dos entrevistados e do entrevistador na obtenção das informações que constituíram os discursos analisados. Mais precisamente, foram utilizadas as noções de discurso, condições de produção e representação, conforme são compreendidas nessa vertente da $\mathrm{AD}$. Tais noções sustentaram a análise das respostas obtidas em entrevistas a pesquisadores do ensino de Física.

Orlandi (1983) considera a linguagem como um trabalho, no sentido de não ter caráter natural, nem arbitrário. Assim pensada, ela é resultado da interação entre o homem e as realidades natural e social, ou seja, constitui-se em produção social e deve ser entendida como uma mediação necessária: “[...] a mediação como relação constitutiva, ação que modifica, que transforma” (ORLANDI, 1983, p. 18), sendo de cunho sócio-histórico os processos envolvidos na constituição da linguagem.

É também a partir do mesmo referencial que conceituamos o discurso como efeito de sentidos entre interlocutores. A autora evidencia que o sentido não é constituído apenas pelos interlocutores, mas está associado à situação e ao contexto histórico-social. Ela ainda comenta a relevância da representação social, associando a significação do processo discursivo às posições em que se situam os interlocutores, tendo em vista as noções de condições de produção e representação:

[...] os interlocutores, a situação, o contexto histórico-social (i. é., as condições de produção) constituem o sentido da seqüência verbal produzida. Quando se diz algo, alguém o diz de algum lugar da sociedade para outro alguém também de algum lugar da sociedade e isso faz parte da significação. Como é exposto por Pêcheux, há nos mecanismos de toda formação social regras de projeção que estabelecem a relação entre as situações concretas e as representações dessas situações no interior do discurso. É o lugar assim compreendido, enquanto espaço de representações sociais, que é constitutivo da significação discursiva. É preciso dizer que todo discurso nasce de outro discurso e reenvia a outro, por isso não se pode falar em um discurso, mas em estado de um processo discursivo, e esse estado deve ser compreendido como resultando de processos discursivos sedimentados, institucionalizados. E finalmente, faz parte da estratégia discursiva prever, situar-se no lugar do ouvinte (antecipação das representações), a partir de seu próprio lugar de locutor, o que regula a possibilidade de respostas, o escopo do discurso. (ORLANDI, 1983, p. 19)

Com base nas noções explicitadas a partir do trabalho de Orlandi, entendemos as respostas obtidas em entrevistas como processos discursivos produzidos em determinadas condições. $\mathrm{Ou}$ seja, admitimos que, na análise, deve-se considerar quem disse, para quem disse, quando disse e de onde disse; além disso, é preciso levar em conta que o que alguém responde não independe de quem perguntou. Em outros termos, quando trabalhamos com linguagem, estamos no domínio do simbólico. Assim, é preciso admitir que as posições de quem verbaliza o discurso, e de quem o ouve não são posições concretas, mas sim imaginárias: suas representações.

Neste estudo, os discursos que nos possibilitaram analisar representações de pesquisadores do ensino de Física foram obtidos em entrevistas semiestruturadas com pesquisadores da área de ensino de Ciências. Trabalhos como o de Nardi e Almeida (2007) evidenciam a relevância dessa técnica para a obtenção de representações de pesquisadores. 


\section{Condições de produção das entrevistas}

A questão formulada aos pesquisadores da área de ensino de Ciências, cujas respostas possibilitaram a constituição dos discursos aqui analisados, foi parte de uma pesquisa mais ampla em que os entrevistados foram selecionados via indicações de seus pares e contatados por correio eletrônico obtido junto às associações de pesquisa que os congregam.

De quase 1.000 correios eletrônicos enviados, pouco mais de 200 foram respondidos com o que havia sido solicitado, a saber, cinco nomes de colegas que eles julgavam estarem atuando na área desde o início e que, na opinião deles, haviam contribuído para a construção do campo. Pouco mais de 500 nomes foram citados, sendo 24 deles entrevistados. Esse número obedeceu a dois critérios: a maior frequência de citação pelos pares e a decisão de que fosse entrevistado pelo menos um pesquisador de cada uma das subáreas do ensino de Ciências: ensino de Biologia, de Física, de Geociências e de Química.

Todas as entrevistas foram realizadas em 2005 pelo mesmo entrevistador: um dos pares dos pesquisadores entrevistados e segundo autor do presente trabalho. Mesmo se admitindo a possibilidade de variações que poderiam ocorrer em decorrência das próprias respostas dos entrevistados, foram estabelecidas as questões básicas.

A pergunta cujas respostas estão aqui em pauta foi a seguinte: A formação e o crescimento da área de ensino de Ciências têm interferido na maneira como se formam professores no Brasil? Por quê? (para respostas negativas) Ou de que maneira? (para respostas positivas). No planejamento da pesquisa, essa questão foi pensada basicamente como a última a ser formulada em cada entrevista.

A leitura do conjunto de respostas mostrou indícios de algumas especificidades próprias a cada subárea do ensino de Ciências, havendo variação conforme os pesquisadores entrevistados: do ensino de Biologia, de Geociências, de Física e de Química. Daí se considerar relevante a centralização da análise numa subárea. Assim, como já dito, são analisadas aqui apenas as respostas de pesquisadores do ensino de Física, subárea que concentrou o maior número de entrevistados. 0 universo analisado inclui respostas de treze pesquisadores: três tinham sua atuação institucional principal na região Sul e dez na região Sudeste do país. Todos lecionavam ou haviam lecionado em universidades públicas, junto a faculdades e departamentos de Educação ou de Física, em disciplinas da Licenciatura em Física e, no caso de alguns deles, do Bacharelado em Física. Todos também tinham ou haviam tido atuação na pós-graduação.

A explicitação das condições de uso dos depoimentos antecedeu cada entrevista, e foi garantido aos entrevistados que eles não seriam identificados quando o estudo fosse publicado. Neste artigo, decidimos utilizar a palavra pesquisador, independentemente de se tratar de um pesquisador ou de uma pesquisadora. No entanto, consideramos interessante registrar que, dentre os treze entrevistados cujas respostas foram analisadas, cinco eram pesquisadoras e oito eram pesquisadores.

É fato também que, nas respostas à questão sobre a interferência da área de ensino de Ciências - enquanto área de pesquisa - na maneira como se formam professores no Brasil, houve comentários que remetiam à relação entre a produção de pesquisas na área de ensino de Ciências e o ensino escolar de uma maneira geral. Mas aqui focalizamos diretamente a formação docente.

\section{Representações dos entrevistados}

A análise qualitativa apoiada na $\mathrm{AD}$ consistiu na leitura prévia de todas as entrevistas, seguida de recortes orientados pela busca de respostas para a questão deste estudo. Dessa maneira, procurou-se compreender se, no imaginário dos pesquisadores, o crescimento da área de ensino de Ciências havia contribuído para a maneira como estão sendo formados professores no país. 
A partir de indícios presentes nos recortes realizados, evidenciamos qualitativamente - e, na medida do possível, de maneira abrangente - como se relacionam os aportes da área de ensino de Ciências com a formação de professores. As porcentagens apresentadas não significam um viés quantitativo do estudo, mas apenas apontam certa tendência de resposta.

Essas porcentagens foram calculadas com base nas respostas sim ou não à questão básica. Na ênfase da maioria dos treze entrevistados, evidenciam-se representações de que houve pequena influência. Apenas dois pesquisadores do ensino de Física $(15,4 \%)$ foram enfáticos ao apontar a existência de influência; dois $(15,4 \%)$ a negaram de imediato; seis $(46,1 \%)$ afirmaram que a influência era pequena; e três $(23,1 \%)$ foram bastante diretos ao condicionar a influência da pesquisa na formação docente à existência de grupos de pesquisa nas instituições formadoras.

É necessário salientar, entretanto, que essas porcentagens mostram apenas as ênfases imediatas dos pesquisadores ao serem questionados. Uns mais, outros menos, todos eles forneceram vários argumentos para suas afirmações, sendo possível notar em suas falas o quanto ponderavam sobre o que estavam dizendo. Alguns deles, inclusive, manifestaram já se terem dedicado anteriormente a estudar academicamente a questão que lhes havia sido formulada e/ou participado de discussões sobre o assunto em encontros da área.

Por outro lado, as duas respostas dos pesquisadores que negaram a influência do acúmulo de pesquisas da área na formação de professores atribuíram a falta de influência à inexistência de demanda por professores mais qualificados e, no mesmo sentido, à desvalorização do professor, com referência ao professor do ensino básico. Nesse último caso, acrescentou-se que havia influência sobre o professor universitário. Das duas respostas que enfatizaram a influência da pesquisa na formação docente, uma apontou como justificativa a educação continuada e a outra situou a influência em disciplinas criadas nas universidades.
Entre os pesquisadores que foram diretos na afırmação de que a influência era pequena, um deles referiu-se à academia e à formação inicial, julgando, entretanto, que a influência era maior na formação em serviço. Tal opinião foi compartilhada por outro entrevistado, que ressaltou ser essa influência local e não em termos amplos.

É interessante notar que, em contraposição a esse argumento, outros pesquisadores julgaram que a influência ocorria na formação inicial, sendo que todos eles se referiram às instituições onde havia pós-graduação em ensino, ou seja, grupos de pesquisa nessa área. Um deles apontou, inclusive, a relevância do professor que realizou pós-graduação, mesmo atuando em universidades em que não há pesquisa, comparativamente aos professores universitários que não têm pós-graduação.

Entre os argumentos para justificar a pequena influência da produção de pesquisas sobre ensino de Ciências na formação de professores, as condições de trabalho no ensino básico foram, sem dúvida, as mais apontadas. Em alguns casos, elas foram o foco da argumentação do pesquisador.

Dada essa pequena sintese inicial, passamos em seguida a comentar trechos das respostas dos pesquisadores. Tais discursos não esgotam o que foi apresentado nas entrevistas, mas evidenciam a diversidade de respostas obtidas. Essa diversidade pode ser notada no grande número de opiniões diferentes contidas nas respostas, tanto nas positivas, quanto nas negativas e também nas ponderações. Algo bastante patente foi a crítica por se pensar unicamente a relação entre resultados obtidos na área e a formação docente, sem levar em conta outros possiveis aspectos intervenientes nessa formação. Em sua maioria, os comentários não se restringiram à formação docente, mas também abrangeram o ensino formal, de maneira geral, ou então focalizaram algum tipo de instituição.

No discurso apresentado a seguir, o entrevistado faz um questionamento com relação à própria pergunta a que estava respondendo. Para esse pesquisador, tal questão, assim 
formulada, estaria subentendendo a ideia de que, apesar de a pesquisa na área ter acumulado resultados, a formação de professores continua ruim. Em sua argumentação, ele lembra outros aspectos que influenciariam o ensino de Ciências, como o salário do professor, de responsabilidade governamental:

[...] não se pode pensar que vai ser a área, ou a pesquisa em ensino de Ciências, que vai ser responsável pela formação de professores [...] essas questões educacionais são coisas de política governamental. [...] 0 professor vai ter um salário digno ou ele vai continuar trabalhando 50 horas por semana? Não adianta fazer mil pesquisas, enquanto tiver professor dando aula 50 horas por semana. [...] não tem pesquisa, não tem área consolidada que vá contribuir pra isso se não tiver uma política governamental.

Falando da posição de pesquisador que ocupa, ele manifesta sua representação sobre a necessidade de o professor dar menos aulas para que a pesquisa possa influenciar sua formação. Refere-se, assim, à formação continuada e atribui o número excessivo de aulas ao salário, que é responsabilidade do governo.

Nas representações de outro pesquisador, um fator que deveria ser considerado para se pensar a relação da pesquisa com o ensino de Ciências em sala de aula é a estrutura curricular da escola. Para justificar a ausência de mudanças na escola pública, ele remete ao número de aulas:

[...] isso não quer dizer que a Física na escola pública... a escola... esteja boa. [...] Com duas aulas por semana, você não dá nada! Duas, ou uma aula por semana!

Outro entrevistado, por sua vez, considerou que não seria possível ensinar Física apropriadamente com uma aula por semana, situação existente em algumas escolas à época da entrevista:
[...] não queira essa relação, porque essa relação não existe. [...] se a gente soubesse ensinar Física com 50 minutos, uma vez por semana, nós seriamos os maiores charlatões certo?

No fato de alguns pesquisadores manifestarem representações que apontaram fatores supostamente externos à pesquisa em ensino de Ciências como determinantes da influência de tal pesquisa no ensino de sala de aula, notamos que, embora essas manifestações não sejam otimistas quanto a uma influência direta da pesquisa, trata-se de uma preocupação desses pesquisadores. Várias respostas indicam suas reflexões a esse respeito, como a seguinte:

[...] a pós-graduação em ensino de Física, já há tantos anos, em várias capitais, né? [...] pelo menos, nós temos ainda muito pouca divulgação disso... penetração disso, nas escolas secundárias [...]. Na sala de aula, o aluno continua achando que o importante é decorar a fórmula; ele não chega a entender o fenômeno.

Entretanto, conforme já comentamos, também houve respostas segundo as quais teria ocorrido certa interferência. Como exemplo, no trecho a seguir, o pesquisador inicialmente menciona condições de produção externas à escola como determinantes da não interferência da pesquisa no ensino de sala de aula, como a cobrança de aprovação no vestibular associada à necessidade de o programa ser trabalhado integralmente. Ele também supõe, porém, que em alguns casos a interferência teria ocorrido:

[...] eu acho que é um pouco difícil ainda. [...] ele [o professor] está sobrecarregado de uma... de um discurso comercial, dos colegas que querem aprovação no vestibular e veem que tem que dar o programa todo, em determinados esquemas, com determinadas apostilas [...]. Então, esse trabalho de pesquisa... de entendimento de como o aluno está... 
como é que ele está desenvolvendo, essa... esse conhecimento dele... um trabalho mais ligado à aprendizagem significativa [...]. Isso acaba não... não tendo tempo de chegar à sala... a maioria das salas de aula, mas eu acho que... que a gente tem casos com êxito.

0 conjunto de excertos apresentado a seguir constitui um quadro configurativo de grande parte das condições de produção intervenientes no ensino, segundo as representações dos pesquisadores. São trechos que evidenciam a diversidade de posições a esse respeito entre tais pesquisadores. Tendo em vista a perspectiva teórica assumida neste estudo, os recortes das falas dos entrevistados, pensados como discursos, são efeitos de sentido produzidos nas condições de produção das entrevistas, condições estas que incluem suas memórias discursivas, ou seja, outros discursos ditos em outros lugares e de outras maneiras, além das condições imediatas de produção desses discursos. Devemos inclusive lembrar que o entrevistador é um dos pares dos entrevistados, havendo a possibilidade de tais discursos terem sido regulados por sua presença.

0 retorno pra sala de aula tem sido... relativamente pouco comparado com... com o grosso do trabalho, né?

[...] a comunidade tem um impacto grande na... na... formação continuada, mas aí tem um problema... não tem uma correspondente apropriação dos professores desse conteúdo para poder usar na sala de aula.

[...] o professor formado num local com mais qualificação, eu acho que ele vai ser um melhor professor; mas, às vezes, as condições, né? [...] Eu acho que o grande problema no Brasil é... as condições... entra o tempo que o aluno passa na escola, no ensino fundamental e médio, o nível econômico desses alunos... as condições de trabalho dos professores.
[...] pode ser, sim, que haja uma certa influência, tendências, visões etc. [...] e há coisas mais recentes, através de... de... políticas oficiais. [...] você produz parâmetros, parâmetros complementares, diretrizes, leis... E quando chega à base... lei, ora lei... os parâmetros... ou leu e não gostou, ou achou interessante, mas não sabe como pôr em prática aquilo... Os quadros que nós formamos... estou dizendo, esses quadros alcançam muito pouco a base escolar.

[...] eu acho que ainda é pequena a influência dessas iniciativas, por uma razão, entre outras [...]. Entre nós, o magistério continua a ser uma atividade considerada ainda pouco importante. Além disso, a escola pública, em nível secundário, ela é esquecida.

[...] e a profissão de professor não foi valorizada, do ponto de vista oficial. Então, eu acho que houve um desencontro na sociedade entre a valorização, do ponto de vista oficial [...] porque a implantação da pós-graduação é uma valorização... né? Mas eu acho que não houve ainda um encontro que transforme, né?

Qual foi o nosso efeito [...]. A gente tem que ser modesto, pra saber que foi muito pequeno. No entanto... também... a gente tem que se conscientizar de que educação é um processo que envolve toda a população... e é portanto muito complexo, muito lento esse desenvolvimento.

[...] e esse material que nós temos, eu acho que está ficando, assim, um pouco ocioso. [...] a Secretaria de Educação tinha que adquirir aquilo por preço menor, [...] penetração disso nas escolas secundárias... isso que eu acho que tem que ser mais.

[...] eu acho que esse assunto de sala de aula e da contribuição, eu acho que é fundamental, mas as pessoas que fazem isso 
- e nós, como professores ou licenciandos - deveríamos, realmente, ser capazes de passar isso com muita seriedade e demonstrar limitações. E demonstrar não é qualquer coisa. Um pouco de trabalho, um pouco de energia gasta pra poder preparar material para fazer um estudo, um pequeno estudo bibliográfico...

[...] há um potencial muito grande na nossa área de... fazer essa... de oferecer essa contribuição mais... macroscópica. [...] a gente vê hoje as pessoas trabalhando mais, evidentemente... muitos não trabalhando nada e... há pressa... uma rapidez... a gente tem que ler coisas pequenas, os alunos se queixam, muitas vezes de um texto de vinte páginas que eles têm que ler de uma aula pra outra... Então, há uma dificuldade que nós temos de... suplantar a [...] estamos na era do conhecimento de uma elite que produziu esse conhecimento, e temos potencial enorme pra difundi-lo, de maneira muito mais fácil hoje, através da internet, através dos meios eletrônicos de comunicação, mas nós temos um analfabetismo... massivo da população... do contingente da população mundial. Então, pra ler a internet, você precisa ter filtros, demandam um estudo, uma leitura sofisticada; senão você naufraga... Eu acho que boa parte naufraga na internet, não navega nela... não é?

$\mathrm{Na}$ leitura desses recortes, reconhecemos representações que indicam o pouco retorno da pesquisa para a sala de aula, pela distinção entre impacto na formação continuada e uso do conteúdo apreendido pelo professor. Também são focalizadas circunstâncias de produção impeditivas da influência das pesquisas efetuadas, tais como o tempo do aluno na escola, seu nível socioeconômico e as condições de trabalho do professor. Ainda encontramos representações centralizadas nos parâmetros curriculares e no reconhecimento dos limites de sua eficácia na escola. Estão entre as condições de produção limitantes apontadas nos discursos dos pesquisadores: a pouca importância que se dá ao magistério, o esquecimento da escola pública e o desencontro entre a valorização da pós-graduação e a profissão de professor.

Como fator externo limitante da interferência da pesquisa no ensino escolar, foi apontada a complexidade da escola, bem como o fato de ela envolver toda a população. Também houve a indicação de uma possível solução: a distribuição nas escolas, pela Secretaria de Educação, do material produzido na área. Já a representação do penúltimo recorte aponta como limite para a interferência o próprio trabalho dos pesquisadores, salientando a necessidade de se demonstrarem as limitações no trabalho com os licenciandos. Por sua vez, o último dos recortes destacados nessa sequência extrapola a questão do Brasil para uma imagem da população mundial e da inserção diferencial de partes da sociedade no conhecimento nela produzido.

No que se refere a respostas mais diretas ao questionamento sobre a interferência da área de ensino de Ciências na maneira como se formam professores no Brasil, a seguinte fala apresenta uma representação de que a interferência existe. Ao mesmo tempo, ela parece subentender fatores limitantes para a ação da área, tal como observamos em algumas das falas já apresentadas.

Então... agora... chega sim, aos professores; e esse é o maior drama dos professores... porque eles sabem o que fazer. [...] Então, eu acho que... chega .... dentro das limitações que nos é posta...

Já nos trechos a seguir, aparece delimitada a abrangência da interferência:

Então... eu diria que houve um efeito em centenas, milhares, talvez, de professores, mas, não ainda, nas centenas e milhares necessários... 
[...] não digo que teve um impacto... um impacto quantitativo muito grande, não é? Isso, de novo, eu digo que... a dificuldade que a gente tem... de divulgar, de forma séria...

Outros pesquisadores admitiram que a interferência ocorreria, mas basicamente nos professores do ensino superior:

[...] eu acho que há um impacto na formação de professores universitários... agora, na atuação dos professores em sala de aula...

[...] mesmo as universidades menores estão sendo obrigadas a qualificar o seu pessoal, ou a contratar gente qualificada, a nível de mestrado, pelo menos... então, eu acho que a qualidade das pessoas que trabalham na formação de professores tá... tá aumentando... agora, eu também acho que, se me perguntasse: e o efeito no ensino? [...] Mas aí a coisa é mais complicada.

Nos recortes a seguir, notamos a maneira bem direta como dois pesquisadores entendiam a atuação da universidade em mudanças decorrentes da pesquisa em ensino de Ciências:

[...] a modificação no currículo da licenciatura introduziu muito mais os resultados das pesquisas em muitas, muitas disciplinas, várias... pelo menos eu, todo ano, tenho várias disciplinas que, de alguma forma, dizem respeito ao conhecimento que a própria comunidade produziu, né?

[...] na medida em que um aluno da licenciatura... começa a se incorporar com um grupo de pesquisa em ensino dentro de uma universidade, ele começa a... entrar um pouco no meio acadêmico... ele começa a ter outros interesses, interesse em fazer o mestrado, em fazer um doutorado, e ele não é aquele professor que vai pegar as 40, 50 horas semanais, mas ele é um atuante também na sala de aula. Então, eu acho que muitas coisas estão sendo passadas pra sala de aula [...]. Hoje nós temos materiais didáticos de Física que têm incorporado essa pesquisa. Acho que agora... começa... a aparecer trabalho mais sistemático, mas claro que não é o país inteiro; o país é muito grande.

Ainda no que se refere à interferência da pesquisa na formação de professores, consideramos relevante registrar que um dos pesquisadores, logo no início da entrevista, disse já se ter dedicado a um estudo sistemático sobre essa formação e sobre o que seria necessário para que a pesquisa tivesse efetivamente interferência no ensino. Essa manifestação reforça a opinião dos autores deste estudo de que nele foi questionado um assunto que fazia parte do universo de preocupações dos pesquisadores da área.

Também é interessante o registro de que, mesmo não tendo o entrevistador se referido especificamente a recursos produzidos na área, dois dos treze entrevistados direcionaram suas falas para os periódicos nela publicados:

Você leva em conta também as revistas, então eles... essa produção toda deveria ter uma presença maior no ensino, né?... fundamental e médio.

[...] uma revista que temos que dar muito crédito [cita os editores do periódico]... bem, eu não sou personalista, mas eu gosto de dar realmente crédito às pessoas que merecem [...], porque o trabalho de formiguinha que têm feito, ao longo de todos esses anos, deu uma mudança, de quanto para qualitativo, fabulosa; e a revista, que sempre vi e ainda vejo, que os professores e os estudantes, me lembro, brigam por ela, querem ter ela.

Para finalizar as representações subentendidas nas falas dos pesquisadores entrevistados, reproduzimos a seguir um caso relatado por um deles. Ao contá-lo, ele disse estar-se 
lembrando do que ouvira de um professor palestrante num dos simpósios de ensino de Física:

[...] contando que, quando ele era aluno da licenciatura, teve um professor na disciplina, se não me falha a memória, de Estrutura da Matéria, que, logo no início do curso, perguntava a cada aluno se ele era licenciatura ou era bacharelado. E quando o aluno falava que era licenciatura, ele já dizia: "Você está reprovado". Isso é um elitismo incompreensível. Então, esse professor disse como esse tipo de atitude marcou a ele e a outros colegas, que se sentiam discriminados, antecipadamente, por uma ideia, por uma visão deprimente da tarefa de ensinar, que era tida, por essa pessoa, e é tida ainda, por alguns outros físicos... como uma atividade menor.

Como finalização dos recortes de falas dos pesquisadores, recortes estes aqui entendidos como discursos que apontam indícios de suas representações, tal caso permite que se avalie a relevância que pode ter, para a autoimagem do futuro professor, o imaginário social sobre a profissão do docente do ensino básico manifesta por aquele físico, seu professor. Tal imaginário social é atribuído pelo pesquisador entrevistado a alguns físicos, mas pode ser estendido a parcelas maiores da população. Trata-se de algo que certamente contribui para a construção de autoimagens, as quais precisam ser somadas aos fatores limitantes da influência da pesquisa em ensino de Ciências na formação do professor e, consequentemente, em seu desempenho profissional.

\section{Considerações finais}

Neste estudo, buscou-se compreender discursos de pesquisadores do ensino da Física obtidos em entrevistas. Foram destacados discursos em que esses pesquisadores manifestaram algumas de suas representações sobre as possibilidades de interferência da pesquisa em ensino de Ciências na maneira como se formam professores no Brasil. Entretanto, eles não se limitaram a responder estritamente à questão formulada, mas estenderam suas respostas, fazendo comentários que incluíram possibilidades e limites da pesquisa e da ação docente em diferentes níveis do ensino. Cabe aqui o reconhecimento de um processo de historicização. Segundo Orlandi (2012, p. 176),

[...] é a necessidade da versão oral, da imagem enunciativa, que vai tomando suas distâncias, que vai constituindo a historicidade, a condição de possibilidade do trabalho da interdiscursividade.

Em tal processo, a diversidade de posições dos pesquisadores pode ser notada nos argumentos utilizados, presentes em suas memórias discursivas e manifestos em seus discursos. Nas manifestações de um mesmo argumento por mais de um pesquisador, pode-se observar ênfases diferentes.

A partir das condições de produção das entrevistas, mas também levando em conta outras condições de produção pertinentes às suas memórias discursivas, notamos a natureza diferenciada das representações dos treze pesquisadores, o que aponta para a diversidade de suas reflexões e pode ser atribuído a concepções educacionais, apoios teóricos, condições de trabalho e histórias de vida no meio educacional, aspectos que são diferentes de uns para outros.

Aqui convém relembrar que os pesquisadores entrevistados foram os mais votados por seus pares quando questionados sobre quem consideravam que estava na área de ensino de Ciências desde seu início, tendo inclusive contribuído para a construção dessa área. Entretanto, em seu conjunto, os aspectos abordados pelos entrevistados constituem um amplo quadro configurativo de representações que pode ser elemento de reflexão para outros pesquisadores. Acreditamos também que tais representações têm potencial de contribuição para efetivas interferências na forma de realização de políticas públicas, sem a 
necessidade do uso de prescrições e cada vez menos com recomendações vazias.

Além disso, a diversidade de fatores e argumentos que constituíram as respostas é bastante positiva. Ela é um indício da pluralidade de resultados de investigação, de linhas de pesquisa e posições assumidas por um grupo significativo de pesquisadores da área de ensino de Ciências. Trata-se de uma diversidade de posições manifestas quando eles foram interrogados sobre uma questão crucial do ensino - a formação docente -, o que em muito enriquece essa área.

\section{Referências}

ALMEIDA, Maria José P. M. Prescrições e recomendações ao professor na solução de problemas do ensino na educação em ciências. Ciência \& Ensino, v. 1, n. 1, p. 47-51, dez. 2006.

Meio século de educação em ciências: foco nas recomendações ao professor de física. São Paulo: LF Editorial, 2012.

ALVES, Nilda (Org.). Formação de professores: pensar e fazer. 8. ed. São Paulo: Cortez, 2004. (Questões da Nossa Época, 1).

BASTOS, Fernando; NARDI, Roberto (Orgs.). Formação de professores e práticas pedagógicas no ensino de ciências: contribuições da pesquisa na área. São Paulo: Escrituras, 2008.

BECKER, Fernando. A epistemologia do professor: o cotidiano da escola. 3. ed. Petrópolis: Vozes, 1995.

BRZEZINSKI, Iria (Org.). Formação de professores: um desafio. Goiânia: UCG, 1997.

CADERNOS CEDES. Campinas: CEDES, n. 44 (0 professor e o ensino: novos olhares), 1998.

CARVALHO, Anna Maria P.; GlL-PÉREZ, Daniel. Formação de professores de ciências: tendências e inovações. Tradução de Sandra Valenzuela. São Paulo: Cortez Editora, 1993. (Coleção Questões da Nossa Época, v. 26).

CATANI, Denice B. et al. Universidade, escola e formação de professores. São Paulo: Brasiliense, 1986.

CONTRERAS, José. A autonomia de professores. Tradução de Sandra Trabucco Valenzuela. São Paulo: Cortez, 2002.

EDUCAÇÃO \& SOCIEDADE: Revista Quadrimestral de Ciência da Educação. Campinas: CEDES, n. 68 (Formação de profissionais da educação: políticas e tendências), 1999.

EDUCAÇÃO \& SOCIEDADE: Revista Quadrimestral de Ciência da Educação. Campinas: CEDES, n. 74 (Dossiê "Os saberes dos docentes e sua formação"), 2001.

FACCI, Marilda G. D. Valorização ou esvaziamento do trabalho do professor? Um estudo crítico-comparativo da teoria do professor reflexivo, do construtivismo e da psicologia vigotskiana. Campinas: Editores Associados, 2004. (Coleção Formação de Professores).

FERACINE, Luiz. 0 professor como agente de mudança social. São Paulo: EPU, 1990. 
GATTI, Bernadete. Formação de professores e carreira: problemas e movimentos de renovação. São Paulo: Autores Associados, 1997.

GERALDI, Corinta M. G. et al. (Orgs.). Cartografias do trabalho docente. Campinas: Mercado de Letras; Associação de Leitura do Brasil, 1998.

GIOPPO, Christiane. A produção do saber docente no ensino de ciências: uma proposta de intervenção. Curitiba: IBPEX, 1999.

GIROUX, Henry A. Os professores como intelectuais: rumo a uma pedagogia crítica da aprendizagem. Tradução de Daniel Bueno. Porto Alegre: Artes Médicas, 1997.

GOERGEN, Pedro; SAVIANI, Dermeval (Orgs.). Formação de professores: a experiência internacional sob o olhar brasileiro. Campinas: Autores Associados; São Paulo: NUPES, 1998.

KINCHELOE, Joe L. A formação do professor como compromisso político: mapeando o pós-moderno. Tradução de Nize Maria Campos Pellanda. Porto Alegre: Artes Médicas, 1997.

KRASILCHIK, Myriam. 0 professor e o currículo das ciências. São Paulo: EPU; EDUSP, 1987.

MARTINS, Anita Viviani Martins. 0 professor como agente político. São Paulo: Edições Loyola, 1984.

MENEZES, Luis Carlos (Org.) Formação continuada de professores de ciências no âmbito ibero-americano. Campinas: Autores Associados; São Paulo: NUPES, 1996a.

(Org.). Professores: formação e profissão. Campinas: Autores Associados; São Paulo: NUPES, 1996b.

MION, Rejane A.; SAITO, Carlos H. Investigação-ação: mudando o trabalho de formar professores. Ponta Grossa: Gráfica Planeta, 2001.

NARDI, Roberto; ALMEIDA, Maria José P. M. Investigação em ensino de ciências no Brasil segundo pesquisadores da área: alguns fatores que Ihe deram origem. Pro-Posições, Campinas, v. 18, n. 1 (52), p. 213-226, jan./abr. 2007.

NARDI; Roberto; BASTOS, Fernando; DINIZ, Renato E. da Silva (Orgs.). Pesquisas em ensino de ciências: contribuições para a formação de professores. São Paulo: Escrituras, 2004.

ORLANDI, Eni P. Para quem é o discurso pedagógico. In: São Paulo: Brasiliense. 1983. p. 18-31.

A linguagem e seu funcionamento: as formas do discurso.

. Discurso em análise: sujeito, sentido, ideologia. Campinas: Pontes, 2012.

OSTERMANN, Fernanda; MOREIRA, Marco Antonio. A física na formação de professores do ensino fundamental. Porto Alegre: Editora da Universidade, 1999.

PEREIRA, Ricardo Marcelo. 0 avesso do modelo: bons professores e a psicanálise. Petrópolis: Vozes, 2003.

PERRENOUD, Philippe. A prática reflexiva no ofício de professor: profissionalização e razão pedagógica. Tradução de Claudia Schilling. Porto Alegre: Artmed Editora, 2002.

PIMENTA, Selma Garrido (Org.). Didática e formação de professores: percursos e perspectivas no Brasil e em Portugal. São Paulo: Cortez, 1997.

RANGEL, Mary. Representações e reflexões sobre o "bom professor”. 3. ed. Petrópolis: Vozes, 1996.

RIBEIRO, Maria Luisa Santos. A formação política do professor de $1^{\circ}$ e $2^{\circ}$ graus. São Paulo: Cortez Editora, 1987.

ROSA, Maria Inês P. Investigação e ensino: articulações e possibilidades na formação de professores de ciências. ljuí: Editora Unijuí, 2004. (Coleção Educação em Química). 
ROSA, Maria Inês P. Formar: encontros e trajetórias com professores de ciências. São Paulo: Escrituras, 2005.

SELLES, Sandra E.; FERREIRA, Márcia S. (Orgs.). Formação docente em ciências: memórias e práticas. Niterói: EDUFF, 2003.

TARDIF, Maurice; LESSARD, Claude (Orgs.). 0 ofício de professor, perspectivas e desafios internacionais. Tradução de Lucy Magalhães. Petrópolis: Vozes, 2008.

Recebido em: 01.03.2012

Aprovado em: 10.12.2012

Maria José P. M. de Almeida é professora titular no Departamento de Ensino e Práticas Culturais da Universidade Estadual de Campinas (Unicamp), líder do Grupo de Estudo e Pesquisa em Ciência e Ensino e atua junto ao programa de pós-graduação da Faculdade de Educação e ao Programa de Pós-Graduação Multiunidades em Ensino de Ciências e Matemática (PECIM), ambos da Unicamp.

Roberto Nardi é professor adjunto no Departamento de Educação da Faculdade de Ciências da Universidade Estadual Paulista "Júlio de Mesquita Filho" (UNESP), líder do Grupo de Pesquisa em Ensino de Ciências e atua no Programa de PósGraduação em Educação para a Ciência, da UNESP. 
